\title{
Synchronized Control for Five-Story Building under Earthquake Loads
}

\author{
Javad Mesbahi ${ }^{1}$ and Alaeddin Malek ${ }^{2}$ \\ ${ }^{1}$ Department of Mathematics, Payame Noor University, Tehran 19395-4697, Iran \\ ${ }^{2}$ Department of Applied Mathematics, Faculty of Mathematical Sciences, Tarbiat Modares University, P.O. Box 14115-134, \\ Tehran 1411713116, Iran \\ Correspondence should be addressed to Alaeddin Malek; mala@modares.ac.ir
}

Received 22 February 2015; Revised 14 April 2015; Accepted 15 April 2015

Academic Editor: Ray K. L. Su

Copyright (C) 2015 J. Mesbahi and A. Malek. This is an open access article distributed under the Creative Commons Attribution License, which permits unrestricted use, distribution, and reproduction in any medium, provided the original work is properly cited.

\begin{abstract}
Synchronized control is implemented for a five-story building under earthquake loads and its capabilities are investigated for protection of building under earthquake. In this regard, we applied $\mathrm{H}_{2} / \mathrm{LQG}$ control algorithm in form of synchronized control for structural vibration reduction. Simulation results of modeling indicated that not only the provided control is able to reduce the responses of vibrations for the structure, but also it is even capable of supplying the objectives of synchronized control at the same time. Numerical results for uncontrolled, traditional $\mathrm{H}_{2}$ /LQG control and synchronized control coupled with $\mathrm{H}_{2} / \mathrm{LQG}$ algorithm are presented. It is shown that for El Centro and Bam earthquakes the synchronized control is more efficient to reduce damage to the given structures.
\end{abstract}

\section{Introduction}

In the recent years, applying structure controlling technologies for reducing the responses of structure, that is, speed, displacement, acceleration, and force under load of earthquakes or severe winds attracted a lot of attentions. Structure control is classified in different forms including active, passive, semiactive and hybrid controls [1]. In passive control strategy, the vibration force is absorbed by damper. In active control systems, large actuators are used to perform direct control force but, in semiactive systems, the control force is applied indirectly to the structure. The semiactive control system gained more attention, because it can control the performance of the structure satisfactorily, and at the same time it needs less energy to achieve the control objectives. The semiactive actuators are including actuator variable stiffness (AVS) and dampers containing Electrorheological Fluids (ER) or Magnetorheological Fluids (MR) [1,2].

Active and semiactive systems both have actuators, sensors, and controllers in the structure; therefore, they have more intelligent performance than the passive systems for change in the structural and environmental conditions.
In this system, the sensor will collect data from structure during the dynamic loading and send it to the controllers. Then, after process by the controller's algorithm the control force will be determined and will be sent to actuators and the vibrations of structure are controlled.

The objective of controlling algorithms is to determine the control force in optimized way and to deduct the vibration responses of buildings. For example, control algorithms like $\mathrm{LQR}$, pole assignment, sliding mode control, bang-bang control, clipped control, LQG, independent model space control (IMSC), Fuzzy Logic Control (FLC), Genetic Fuzzy Logic Control (GFLC), and Adaptive Neuro-Fuzzy Inference System (ANFIS) can be named. Each one of these systems has specific particulars that are considered to be used based on condition of structures $[1,2]$.

On the other hand, the reduction of the vibration response should be in such a manner that the internal forces of the structure will reach their minimum amount. In this regard, the control algorithm shall be set in a way that it can minimize relative displacement between freedom levels synchronically. On the other hand, they shall be synchronized. 
For example, displacement and drift in a multistory structure shall be reduced at the same time.

Synchronization is a very important issue in most of the controlling systems and it has different definitions [3, 4]. Motion synchronization in multiagent systems with different coordinates and same objective is of great importance [5]. In such applications of control, the performance of system is more dependent on motion synchronization than the correctness of motion in each independent part. The need for synchronized motion will feel when the parts with different coordinates are supposed to move at the same time and the relationship between their relative displacements is important [6]. In most of the experiments while the start and stop times should be synchronized, also the relationship between location and speed between coordinates is very important. The need for improvement in such systems will lead to performing wide researches in this area. The initial researches are in field of motion and indicated that the general performance may be improved through adjustment of error between independent agents [6].

In most of the nonvibrational control models, some agents have the tracking objective but, in vibrational control models, the objective is regulation of outputs or reduction of structure vibration. In fact regulation is a type of tracking but the amount of objective or expected objective is zero [7]. Therefore, based on the explanation, the regulated outputs of the model should be defined in such a manner that they can satisfy the objectives of vibration reduction and, at the same time, they can synchronize the targets.

In this study, a five-story model building was examined to compare control and a traditional active control algorithm $\mathrm{H}_{2}$ /LQG against a mathematical synchronized algorithm coupled with $\mathrm{H}_{2} / \mathrm{LQG}$. This novel form of synchronized control algorithm combines $H_{2}$ /LQG and mathematical synchronized parameters in a novel algorithm. By using this synchronized control algorithm, displacement and relative displacement of floors, as synchronized parameters under earthquake loading is minimized. With the knowledge of the authors there is no previous research in which a structural seismic control is regarded as motion synchronized control problem or in similar perspective.

\section{Synchronized Control Theory}

Consider a multiagent system in which $\mathrm{n}$ agents are participating in one process. Therefore we need a synchronizer for all of the agents. The target of synchronized control is synchronizing all of the agents in such a manner that the agents can maintain a kinematic relationship, that is, the objective of synchronizer [4].

Setting multiagents for maintain kinematic relationship may be performed in form of guiding and locating the agents along the boundary (or curves) in one specific path.

Definition 1. Let $S(\xi, t)$ be a function with boundary $\Gamma(\xi, t)$ in a compact set $\Omega \subseteq \mathbb{R}^{2}$, where $\xi \in \Omega$ stands for a state vector and $t$ the time.
Definition 2. Define $x_{i}(t)$ and $x_{i}^{d}(t)$ as general state and desired state variables in the $i$ th story.

Definition 3. Let $x_{i}^{d}(t)$ be an arbitrary point on $\Gamma$, where $\Gamma\left(x_{i}^{d}, t\right)=0$. Denote $e_{i}(t)$ as an error of the state variable in the $i$ th story by

$$
e_{i}(t)=x_{i}(t)-x_{i}^{d}(t), \quad i=1,2,3,4,5 .
$$

Definition 4. Let an earthquake happen in the period of $t \epsilon$ $\left[t_{0}, t_{\max }\right]$, where $t_{0}$ is an initial time and $t_{\max }$ is the final time of earthquake.

Definition 5. The goal of synchronized control is achieved when for each agent the state variables $x_{i}(t)$ converge to the desired values $x_{i}^{d}(t)$, as $t \rightarrow t_{\max }$; that is, $e \rightarrow 0$ and $\Gamma\left(x_{i}^{d}(t)\right.$, $\left.t_{\text {max }}\right)=0$.

The formulization of synchronizing is different for various issues and for each issue it can be defined in a certain form [4].

\section{3. $\mathrm{H}_{2}$ /LQG Synchronizing Control Algorithm with Feedback of Acceleration}

Equation of motion of a structure under dynamic loads is in the form of a second-order differential equation as follows [10]:

$$
M \ddot{q}(t)+C \dot{q}(t)+K q(t)=B_{0} u(t)+L w(t)
$$

in which $M, C$, and $K$ are matrices of mass, damping, and stiffness of the system, respectively. $q(t)$ is displacement vector, $u(t)$ is control force vector, and $w(t)$ is external disturbance vector (resulting from earthquake or wind load). $B_{0}$ and $L$ are, respectively, force control place and external stimulation matrices. And the state-space model of the equation of motion depends on the choice of coordinates.

In order to gain nodal model of (2), assuming that the mass matrix is not unit, the equation can be rewritten as follows [10]:

$$
\begin{aligned}
\ddot{q}(t) & +M^{-1} C \dot{q}(t)+M^{-1} K q(t) \\
= & M^{-1} B_{0} u(t)+M^{-1} L w(t) .
\end{aligned}
$$

If we define displacement and velocity as variables of state space, $x(t)=\left[\begin{array}{l}q(t) \\ \dot{q}(t)\end{array}\right]$, the state equation will be as follows:

$$
\dot{x}(t)=A x(t)+B_{2} u(t)+B_{1} w(t),
$$

where $A=\left[\begin{array}{cc}0 & I \\ -M^{-1} K & -M^{-1} C\end{array}\right]$ is state matrix, $B_{2}=\left[\begin{array}{c}0 \\ M^{-1} B_{0}\end{array}\right]$ is actuator stimulus place matrix, and $B_{1}=\left[\begin{array}{c}0 \\ M^{-1} L\end{array}\right]$ is disturbance stimulation place matrix.

Consider the following controlling system. It uses feedback acceleration of a system as output [11]:

$$
\begin{aligned}
& \dot{x}(t)=A x(t)+B_{1} w(t)+B_{2} u(t), \\
& z(t)=C_{1} x(t)+D_{11} w(t)+D_{12} u(t), \\
& y(t)=C_{2} x(t)+D_{21} w(t)+D_{22} u(t)+v,
\end{aligned}
$$


where $z$ consists of the system evaluation parameters and $y$ is an output of ideal sensors without any noise. $D_{11}, D_{12}$, and $C_{1}$ are corresponding parameters of $z(t)$ as a regulated output for minimizing the value of the cost function.

They are defined as acceleration, velocity, and displacement (or relative displacement) coefficients in matrix or vector forms. $D_{21}, D_{22}$, and $C_{2}$ are corresponding matrices and a vector for sensors outputs. They are defined based on which sensors are selected:

$$
J=\lim _{\tau \rightarrow \infty} \frac{1}{\tau} E\left[\int_{0}^{\tau}\left(z^{T}(t) Q z(t)+u^{T}(t) R u(t)\right) d t\right],
$$

where $E$ is the expected value and $Q$ and $R$ are positive semidefinite matrices to regulate the evaluation outputs and weighting the control force, respectively.

In the following instead of $J$, two Riccati equations are used; without loss of generality one may assume that the active control force $u(t)$ is proportional to the estimated state variable $\widehat{x}(t)$. That is,

$$
u(t)=-K_{c} \hat{x}(t),
$$

where $K_{c}$ is defined in a way to minimize (6) by proper $u(t)$. For this respect an algebraic Riccati equation which is corresponded with (6) should be solved; $\hat{x}$ is estimated state variable and $K_{c}=B_{2} P$ and $B_{2}$ is defined in (5) and $P$ is the solution of the following Riccati equation to gain controller gain matrix [11]:

$$
A^{T} P+P A-P B_{2} R^{-1} B_{2}^{T} P+Q=0 .
$$

This equation is solved, through introduction of known parameters in MATLAB Control Toolbox; by different $Q$ matrices, a set of different controllers is gained. In order to gain suitable controller for system, it is needed to give proper weights to $Q$ matrix. In this regard, we can weigh important evaluation parameters for the system and place them at one diagonal matrix. This matrix is a weighted matrix.

In the next step standard Kalman filter is used to estimate the system state variables [11]:

$$
\begin{aligned}
\dot{\hat{x}}(t)= & \left(A-K_{\mathrm{KF}} C_{2}\right) \hat{x}(t)+K_{\mathrm{KF}} y(t) \\
& +\left(B_{2}-K_{\mathrm{KF}} D_{22}\right) u(t),
\end{aligned}
$$

where $K_{\mathrm{KF}}=\left(\widetilde{P} C_{2}^{T}+B_{1} Q_{\mathrm{KF}} D_{21}^{T}\right)\left(R_{\mathrm{KF}}+D_{21} Q_{\mathrm{KF}} D_{21}^{T}\right)^{-1}$ is the estimator gain matrix and $\widetilde{P}$ is gained from the below Riccati equation to get the observer gain matrix:

$$
\begin{aligned}
A \widetilde{P} & +\widetilde{P} A^{T}-\left(\widetilde{P} C_{2}^{T}+B_{1} Q_{\mathrm{KF}} D_{21}^{T}\right) \\
& \cdot\left(R_{\mathrm{KF}}+D_{21} Q_{\mathrm{KF}} D_{21}^{T}\right)^{-1}\left(C_{2} \widetilde{P}+D_{21} Q_{\mathrm{KF}} B_{1}^{T}\right) \\
& =-B_{1} Q_{\mathrm{KF}} B_{1}^{T},
\end{aligned}
$$

where $Q_{K F}$ is magnitude of stimulation spectrum density entering system $S_{d d}(\omega)$ and $R_{\mathrm{KF}}$ is magnitude of noise spectral density of measurement. It is supposed that the stimulates entering system are $d$, sensor noises are $v$, and they are not correlated. Thus $\mathrm{H}_{2} / \mathrm{LQG}$ controller will be designed through gaining $K$ and $K_{\mathrm{KF}}$ through using MATLAB Control Toolbox. $u(t)$ is gained using (7) and (9) as follows:

$$
\begin{aligned}
\dot{\hat{x}}(t) & =A_{c} \widehat{x}(t)+B_{c} y(t), \\
u(t) & =C_{c} \widehat{x}(t),
\end{aligned}
$$

where

$$
\begin{aligned}
A_{c} & =A-K_{\mathrm{KF}} C_{2}-B_{2} K+K_{\mathrm{KF}} D_{22} K, \\
B_{c} & =K_{\mathrm{KF}}, \\
C_{c} & =-K_{c}, \\
D_{c} & =0,
\end{aligned}
$$

where $A_{c}, B_{c}, C_{c}$, and $D_{c}$ are the controller dynamic. Now, the evaluation parameters of control algorithm shall be defined in such a manner that, beside the target of output regulation, the synchronization is gained as well. Considering the fact that in structure control the objective is to control structure vibrations, therefore the structure's displacements in different degree of freedoms are considered as state variable error and it is introduced as part of the regulated outputs. The relative displacements between these degrees of freedoms are defined as objective of synchronized control. The objective of synchronized control will lead to synchronizing in displacements and reduction of internal forces.

\section{The Study Model}

In this part, a five-story structure model is considered that is similar to Kajima Shizuoka Building [8]. This building has five active hydraulic actuators that are placed between each two adjacent floors (see Figure 1). First story height is $4.2 \mathrm{~m}$ and height of each of the remaining stories is $3.6 \mathrm{~m}$. The motion equation of this building can be presented by (2), that is, a second-order differential equation.

In this case, $q(t) \in \mathbb{R}^{5}$ is displacement vector, $u(t) \in$ $\mathbb{R}^{5}$ is control force vector, and $w(t) \in \mathbb{R}$ is disturbance vector (caused by earthquakes or wind load). $B_{0}$ and $L$ are control force place and external disturbance place-matrices, respectively, $M, B_{0}, L, C$, and $K$ are defined as follows:

$$
M=10^{3} \times\left[\begin{array}{ccccc}
215.2 & 0 & 0 & 0 & 0 \\
0 & 209.2 & 0 & 0 & 0 \\
0 & 0 & 207.0 & 0 & 0 \\
0 & 0 & 0 & 204.8 & 0 \\
0 & 0 & 0 & 0 & 266.1
\end{array}\right] \text {, }
$$

$$
B_{0}=\left[\begin{array}{ccccc}
1 & -1 & 0 & 0 & 0 \\
0 & 1 & -1 & 0 & 0 \\
0 & 0 & 1 & -1 & 0 \\
0 & 0 & 0 & 1 & -1 \\
0 & 0 & 0 & 0 & 1
\end{array}\right]
$$




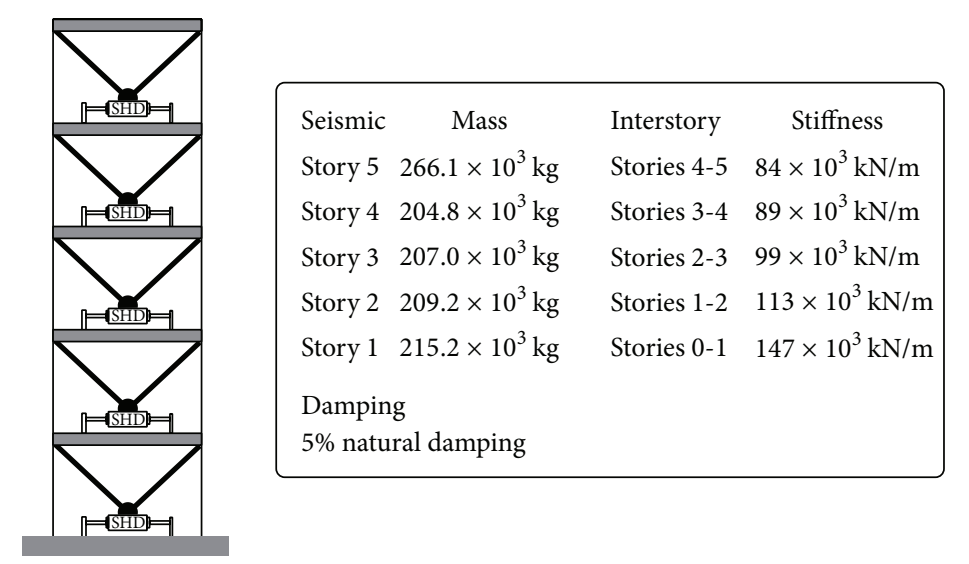

FIGURE 1: A five-story structure model similar to Kajima Shizuoka Building [8, 9].

$$
L=-M\left[\begin{array}{l}
1 \\
1 \\
1 \\
1 \\
1
\end{array}\right],
$$

$C=10^{3}$

$$
\begin{aligned}
& \times\left[\begin{array}{ccccc}
650.4 & -231.1 & 0 & 0 & 0 \\
-231.1 & 548.9 & -202.5 & 0 & 0 \\
0 & -202.5 & 498.6 & -182.0 & 0 \\
0 & 0 & -182.0 & 466.7 & -171.8 \\
0 & 0 & 0 & -171.8 & 318.5
\end{array}\right], \\
& K=10^{6} \times\left[\begin{array}{ccccc}
260 & -113 & 0 & 0 & 0 \\
-113 & 212 & -99 & 0 & 0 \\
0 & -99 & 188 & -89 & 0 \\
0 & 0 & -89 & 173 & -84 \\
0 & 0 & 0 & -84 & 84
\end{array}\right] .
\end{aligned}
$$

The natural damping is considered as $\% 5$ and the natural frequencies of the structure are as follows:

$$
\begin{aligned}
& \omega_{i} \\
& =\{42.5423,36.4257,28.2253,17.7417,6.3343\} \mathrm{rad} / \mathrm{sec},
\end{aligned}
$$

where the mass in kilograms $(\mathrm{kg})$, damping coefficient in $\mathrm{Ns} / \mathrm{m}$, and roughness factor are $\mathrm{N} / \mathrm{m}$. In the modeling, only acceleration of first, third, and fifth stories is used as the partial-state feedback to compute control force.

In order to implement the $\mathrm{H}_{2}$ /LQG control algorithm in the form of synchronized control, in this model, the error of state variables is determined and introduced them in regulated outputs. In this regard, we consider the displacement of each floor as state variable for error determination.

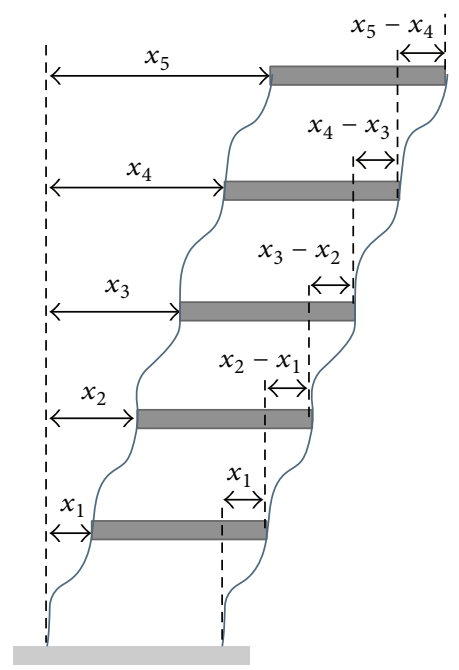

FIGURE 2: Displacement and relevant displacement of the floors.

The expected amounts for each component of the error vector are zero.

Therefore, in the optimistic case, the error of state variables in each moment is equal to the amount of displacement in each floor and thus the objective of control is to tend these values to zero as $t \rightarrow t_{\max }$ (Figure 2). Consider

$$
e=\left(x_{1}, x_{2}, x_{3}, x_{4}, x_{5}\right)
$$

Let us to assume that $\varepsilon_{5 \times 1}$ is a vector that each component stays on the final desired curve as $t \rightarrow t_{\max }$; that is, $\Gamma\left(x_{i}^{d}\right.$, $\left.t_{\max }\right)=0$. By this approach, the relevant displacement between the floors, $\varepsilon$ is considered as synchronizing error (see Figure 2). Relevant displacement between the floors (drift) is determined as follows:

$$
\varepsilon=\left(x_{1}, x_{2}-x_{1}, x_{3}-x_{2}, x_{4}-x_{3}, x_{5}-x_{4}\right) .
$$




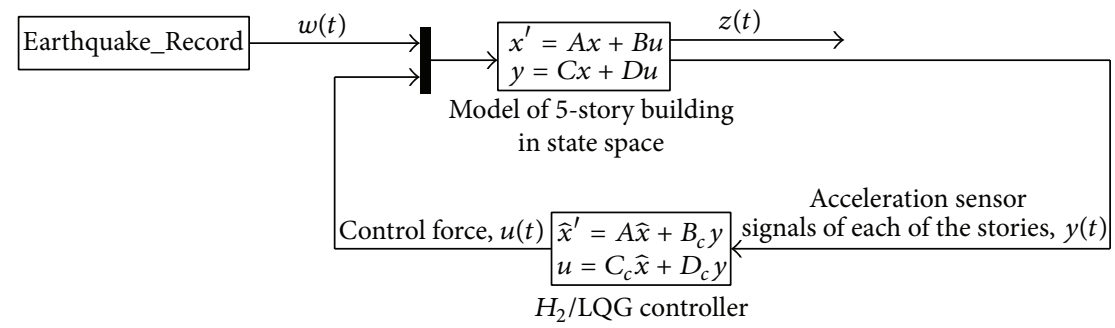

FIgURE 3: Simulink model in MATLAB.

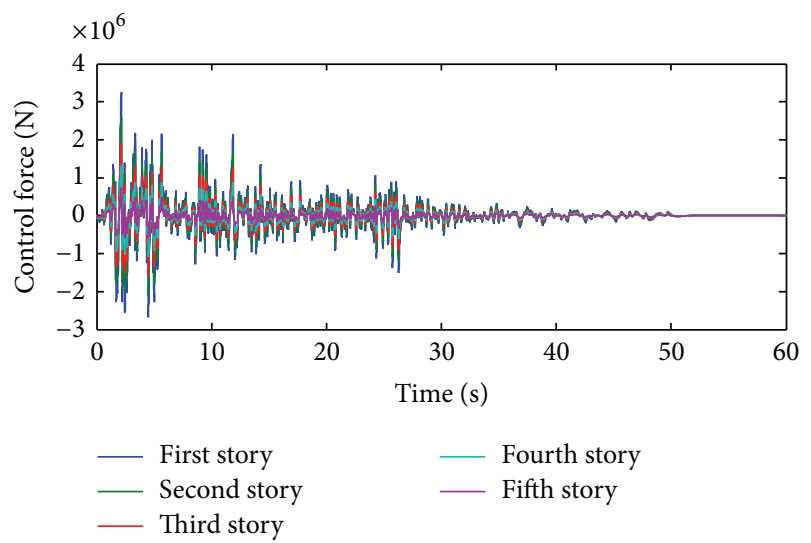

FIGURE 4: Time history graphs of control force for all stories under El Centro Earthquake (1940), when synchronized control coupled with $\mathrm{H}_{2}$ /LQG is used.

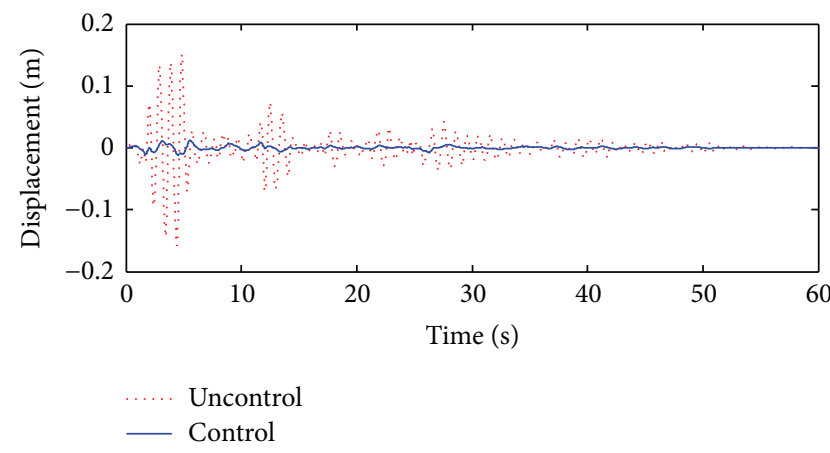

FIGURE 5: Time history graphs of displacement for the fifth floor for uncontrolled and synchronized control coupled with $\mathrm{H}_{2} / \mathrm{LQG}$ algorithm in El Centro Earthquake (1940).

Reduction of relevant displacement between the floors will lead to reducing internal forces of structure. Note that the coupled position error is defined by

$$
E_{c}=(I+\alpha T) e
$$

where $T$ satisfies

$$
\varepsilon=T e
$$

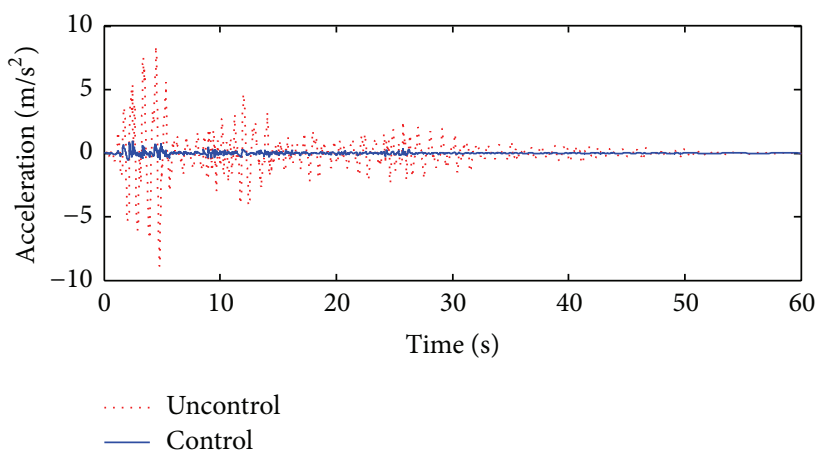

FIGURE 6: Time history graphs of acceleration for the fifth floor for uncontrolled and synchronized control coupled with $\mathrm{H}_{2} / \mathrm{LQG}$ algorithm in El Centro Earthquake (1940).

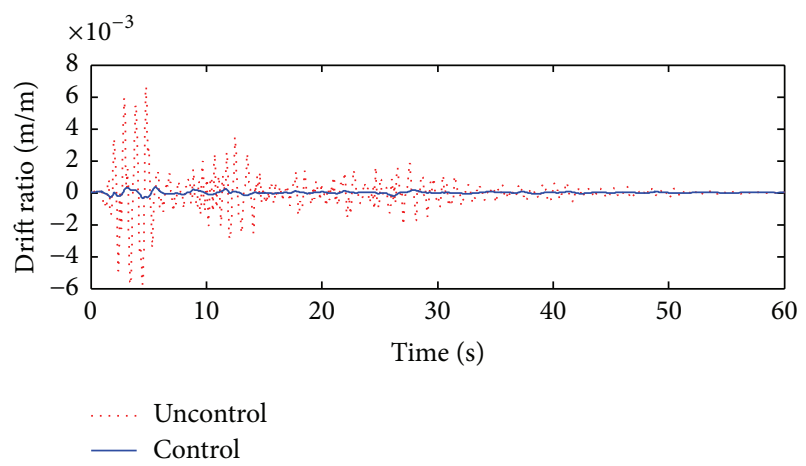

Figure 7: Time history graphs of drift ratio of fifth floor for uncontrolled and synchronized control coupled with $H_{2} /$ LQG algorithm in El Centro Earthquake (1940).

and without loss of generality one may assume

$$
T=\left[\begin{array}{ccccc}
1 & -1 & 0 & 0 & 0 \\
0 & 1 & -1 & 0 & 0 \\
0 & 0 & 1 & -1 & 0 \\
0 & 0 & 0 & 1 & -1 \\
0 & 0 & 0 & 0 & 1
\end{array}\right],
$$

where $\alpha$ is an identical matrix. This means that $(I+\alpha T)$ is an invertible matrix and as $e$ converges to zero $E_{c}$ converges to zero too and vice versa. With respect to the definitions, as 

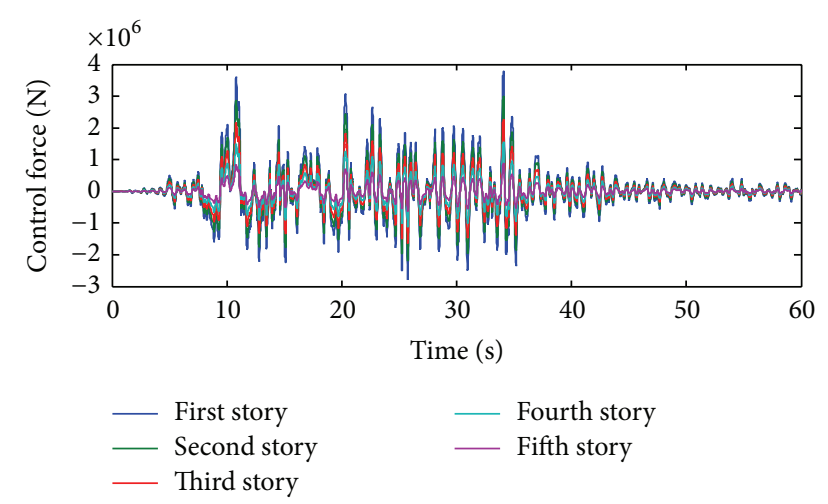

FIGURE 8: Time history graphs of control force for all stories under Bam Earthquake when synchronized control coupled with $\mathrm{H}_{2} / \mathrm{LQG}$ is used.

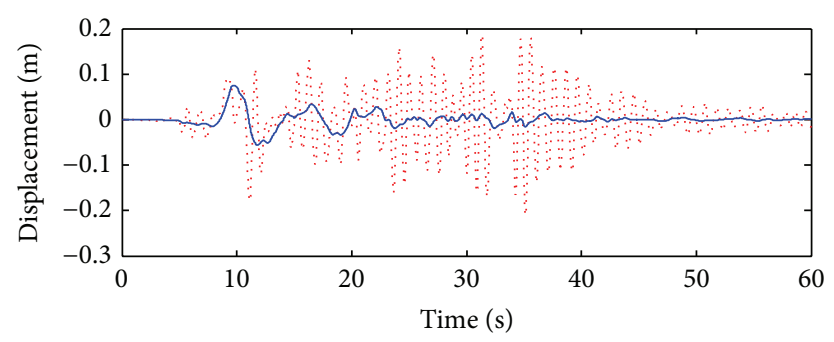

FIGURE 9: Time history graphs of displacement of fifth floor for uncontrolled and synchronized coupled with $\mathrm{H}_{2}$ /LQG algorithm in Bam Earthquake.
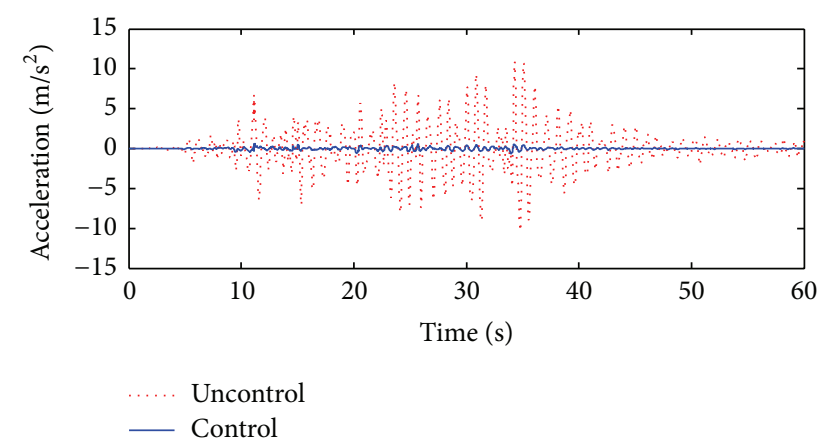

FIgURE 10: Time history graphs of acceleration of fifth floor for uncontrolled and synchronized control coupled with $\mathrm{H}_{2} / \mathrm{LQG}$ algorithm in Bam Earthquake.
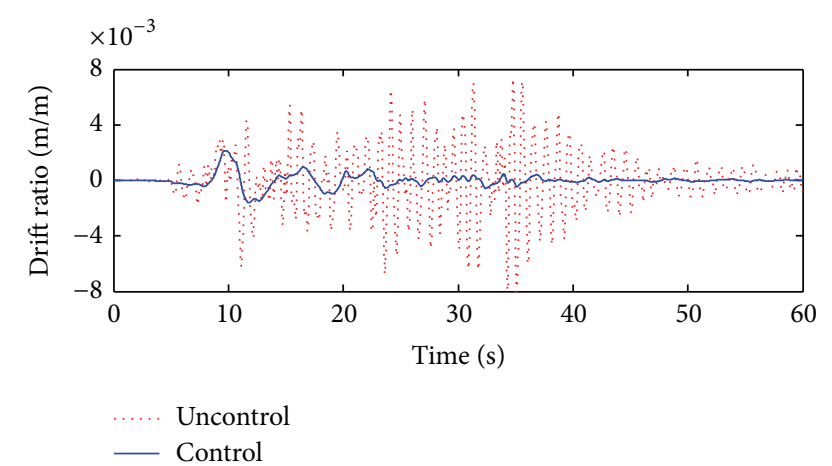

FIgURE 11: Time history graphs of drift ratio of fifth floor for uncontrolled and synchronized control coupled with $\mathrm{H}_{2}$ /LQG algorithm in Bam Earthquake.

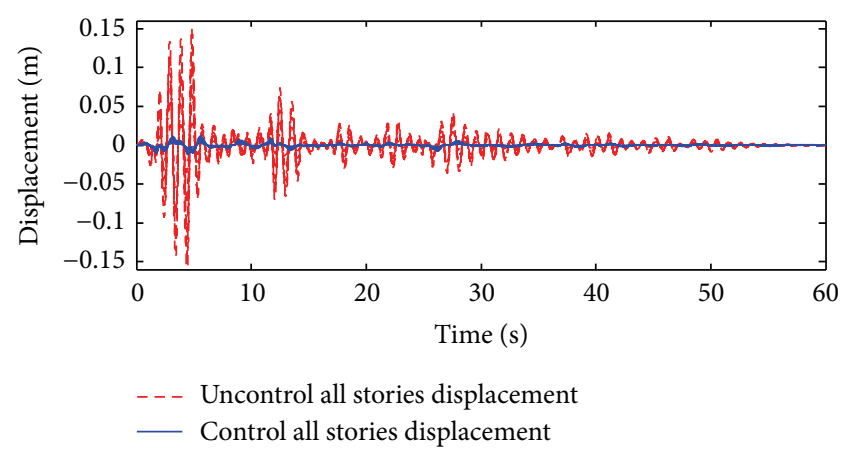

FIgURE 12: Displacements of all five floors for uncontrolled and synchronized control coupled with $\mathrm{H}_{2}$ /LQG algorithm in El Centro Earthquake (1940).

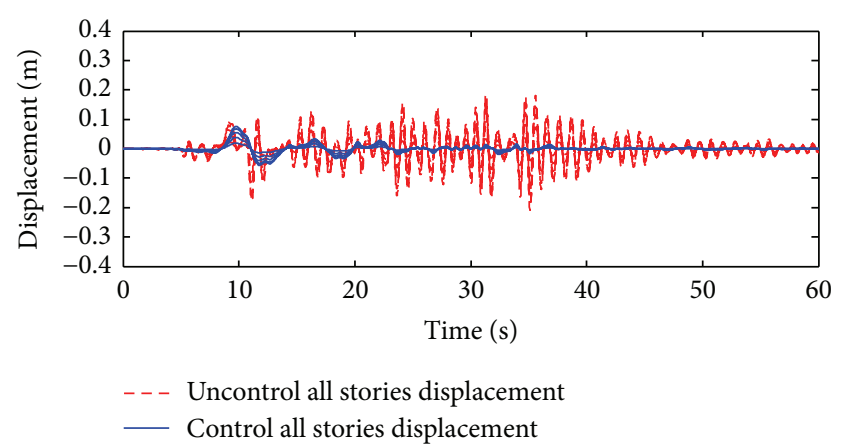

FIGURE 13: Displacement of all five floors for uncontrolled and synchronized control coupled with $\mathrm{H}_{2}$ /LQG algorithm in Bam Earthquake.

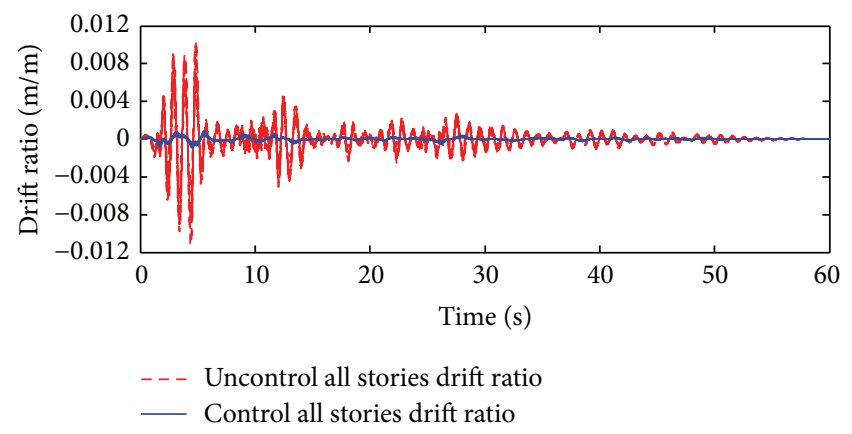

FIGURE 14: Drift ratio of all five floors for uncontrolled and synchronized control coupled with $\mathrm{H}_{2}$ /LQG algorithm in El Centro Earthquake (1940).

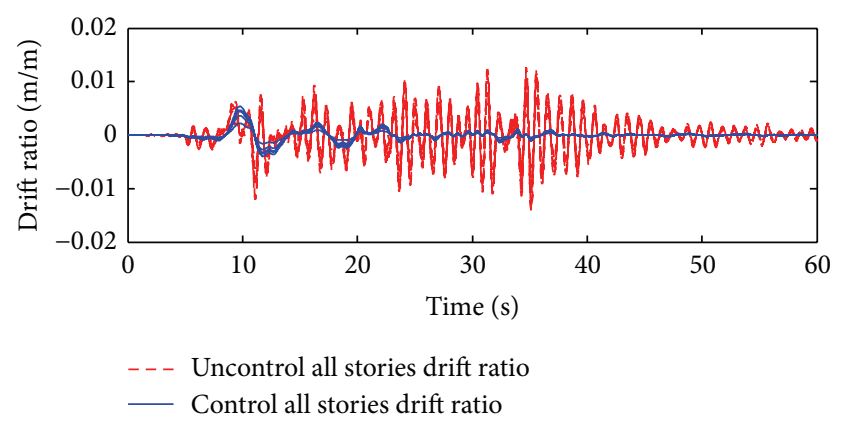

FIGURE 15: Drift ratio of all five floors for uncontrolled and synchronized control coupled with $\mathrm{H}_{2}$ /LQG algorithm in Bam Earthquake. 

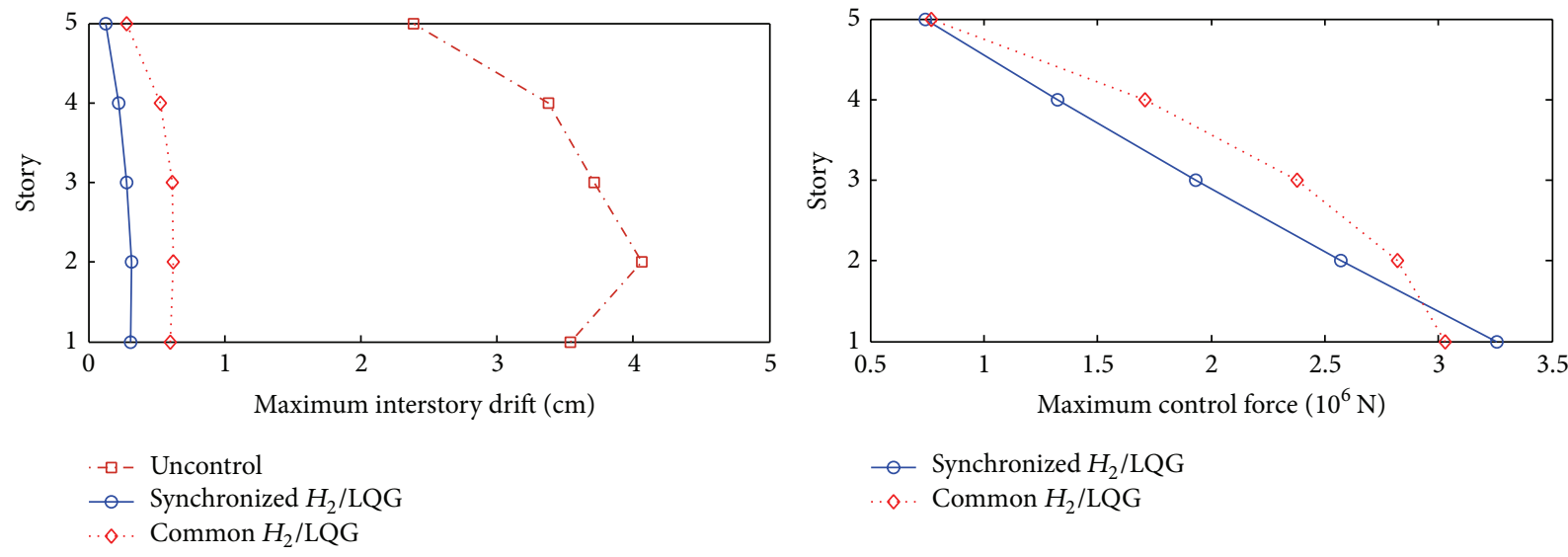

FIGURE 16: Maximum absolute interstory drifts and control efforts in El Centro Earthquake (1940).
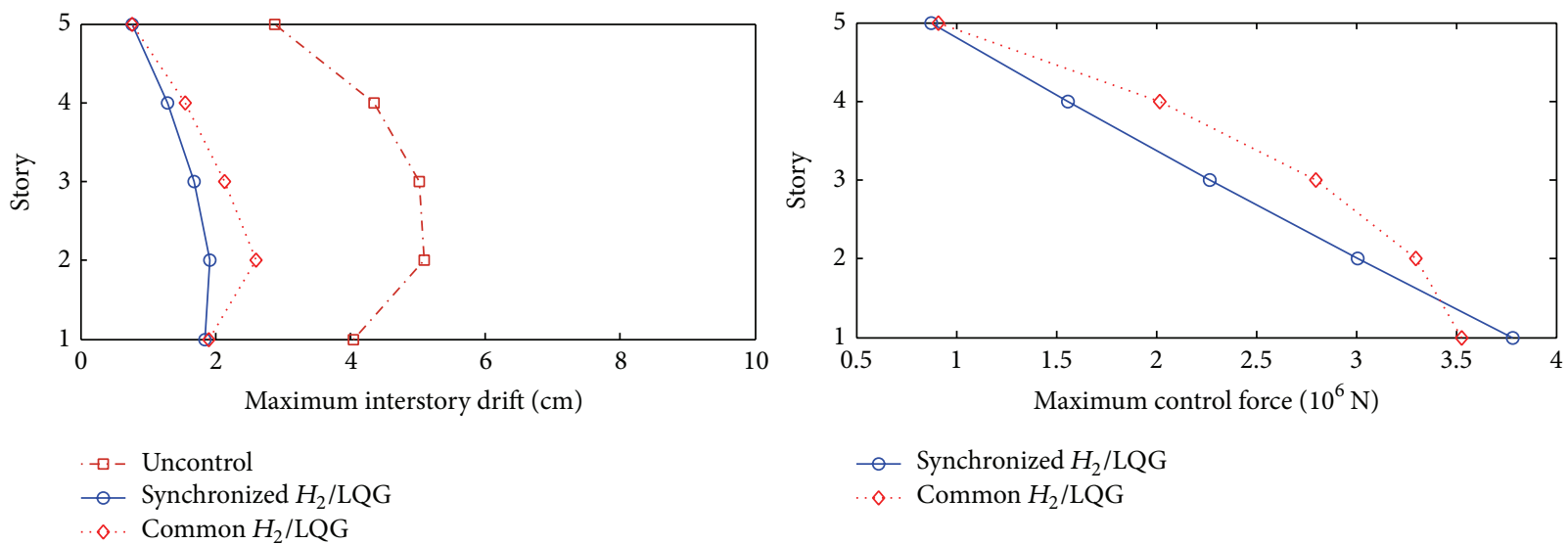

FIGURE 17: Maximum absolute interstory drifts and control efforts in Bam Earthquake.

$t \rightarrow t_{\max }$ coupled position error $E_{c}, e$ and $\varepsilon$ can converge to zero simultaneously [4].

Now, the synchronizing $\mathrm{H}_{2}$ /LQG controller is designed by considering $e$ and $E_{c}$ as the evaluated outputs $z$ from (5). With this one can simultaneously gain the output setting objectives together with synchronized goals. These regulated outputs defined in synchronization $\mathrm{H}_{2}$ /LQG controllers are different from $\mathrm{H}_{2}$ /LQG controllers. That is, in the traditional algorithm there are no synchronization parameters $E_{c}$ and $\varepsilon$. These two algorithms are the same in using first, third, and fifth stories displacement, drifts, and acceleration to compute the regulated outputs. They are different in using different related parameters.

The abovementioned structure is modeled in MATLAB in Simulink environment (see Figure 3). In this model, at first the record of earthquake $w(t)$ is inserted into structure model and then the vibration responses of structure are transferred to controller through acceleration sensors $y(t)$. Finally, proper control force $u(t)$ is applied to the structure and the excessive vibrations are controlled.

\section{Numerical Results and Discussions}

In order to test the designed control algorithm of the structure model in Figure 1, it is analyzed under El Centro Earthquake 1940 and Bam Iran Earthquake 2003 in two forms, with and without controller. The results of analysis are represented for output regulation and synchronizing objectives in structure's time history response graphs. Figure 4 shows control force level under El Centro Earthquake for all stories. Figures 5, 6, and 7 are demonstrating displacement output, acceleration, and drift ratio (ratio of story's drift to the height of the corresponded story) of 5th floor of abovementioned structure in two ways of controlled and uncontrolled under El Centro Earthquake. The reduction values are \%92, $\% 94$, and \%88.7 for the displacement, interstory drift, and acceleration of fifth floor, respectively.

Figure 8 shows control force level under Bam Earthquake for all stories. Figures 9, 10, and 11 are demonstrating displacement output, acceleration, and drift ratio of 5th floor of abovementioned structure in two ways of controlled and uncontrolled under Bam Earthquake. The reduction values 
are $\% 73, \% 73.5$, and $\% 93.64$ for the displacement, interstory drift, and acceleration of fifth floor, respectively.

Considering Figures 5-7 and Figures 9-11, it is clear that the proposed control algorithm was able to prevent excessive vibration of the structure and this reduces the internal forces in the structure. It also reduces the damages to structures during the period of earthquake.

On the other hand, the objectives of synchronized control are supplied in addition to regulation of structure output; that is, with convergence of $E$, $e$ will vanish as $t \rightarrow t_{\max }$. It is demonstrated in Figures 5-7 and Figures 9-11 that the uncontrolled and the controlled solutions for El Centro Earthquake and for Bam Earthquake vanish as $t \rightarrow t_{\max }=$ 60 seconds.

Reduction of displacement in floors and convergence toward zero occurred for all of the floors as error of state variable in the same manner that happens for 5th floor. Figures 12 and 13 display the displacements of all five floors together when both under controlled and uncontrolled forms are considered. On the other hand, after converging, the relative displacement $\varepsilon$ for all floors with the controller vanishes. Figures 14 and 15 demonstrated the drift ratio of all of the five floors in controlled and uncontrolled ways.

For comparison of synchronizing $\mathrm{H}_{2}$ /LQG controller and traditional $\mathrm{H}_{2}$ /LQG controller, the maximum absolute interstory drift and the maximum control force diagrams are supplied in Figure 16 for the El Centro (1940) earthquake and Figure 17 for the Bam earthquake. (Note that Figure 16 is not scaled, and for the scaled El Centro ground motion to 1 the response would be 3.417 times smaller.)

The synchronized $\mathrm{H}_{2} / \mathrm{LQG}$ controller demonstrates its superiority compared to traditional $\mathrm{H}_{2}$ /LQG controller in controlling interstory drifts and also in control force.

\section{Conclusion}

In this study, we proposed a mathematical synchronized control algorithm coupled with $\mathrm{H}_{2}$ /LQG for five-story buildings. The simulation results indicate that, defining the state variable error and synchronized error in regulated outputs, the objectives of synchronized control algorithm can be gained. In addition, after setting these two errors, displacement, drifts, and acceleration values of each floor will decrease significantly and, therefore, the amount of forces on each floor and internal forces of structure will decrease. In general it can be concluded that if conditions for synchronization and regulation are defined properly, the structure can be protected against damage more efficiently.

\section{Conflict of Interests}

The authors declare that there is no conflict of interests regarding the publication of this paper.

\section{References}

[1] G. W. Housner, L. A. Bergman, T. K. Caughey et al., "Structural control: past, present, and future," Journal of Engineering Mechanics, vol. 123, no. 9, pp. 897-971, 1997.
[2] A. Y. Fallah and T. Taghikhany, "Time-delayed decentralized $\mathrm{H}_{2}$ /LQG controller for cable-stayed bridge under seismic loading," Structural Control and Health Monitoring, vol. 20, no. 3, pp. 354-372, 2013.

[3] D. Zhao, Q. Zhu, S. Li, and F. Gao, "Synchronized control of mechanical systems: a tutorial," in Applied Methods and Techniques for Mechatronic Systems, vol. 452 of Lecture Notes in Control and Information Sciences, pp. 1-25, Springer, Berlin, Germany, 2014.

[4] D. Sun, Synchronization and Control of Multiagent Systems, vol. 41, CRC Press, New York, NY, USA, 2010.

[5] D. Zhao and Q. Zhu, "Position synchronised control of multiple robotic manipulators based on integral sliding mode," International Journal of Systems Science, vol. 45, no. 3, pp. 556-570, 2014.

[6] D. Sun, X. Y. Shao, and G. Feng, "A model-free cross-coupled control for position synchronization of multi-axis motions: theory and experiments," IEEE Transactions on Control Systems Technology, vol. 15, no. 2, pp. 306-314, 2007.

[7] D. Sun, C. Wang, W. Shang, and G. Feng, "A synchronization approach to trajectory tracking of multiple mobile robots while maintaining time-varying formations," IEEE Transactions on Robotics, vol. 25, no. 5, pp. 1074-1086, 2009.

[8] N. Kurata, T. Kobori, M. Takahashi, N. Niwa, and H. Midorikawa, "Actual seismic response controlled building with semi-active damper system," Earthquake Engineering and Structural Dynamics, vol. 28, no. 11, pp. 1427-1447, 1999.

[9] J. Rubió-Massegú, F. Palacios-Quiñonero, and J. M. Rossell, "Decentralized static output-feedback $H_{\infty}$ controller design for buildings under seismic excitation," Earthquake Engineering \& Structural Dynamics, vol. 41, no. 7, pp. 1199-1205, 2012.

[10] W. Gawronski, Advanced Structural Dynamics and Active Control of Structures, Springer, New York, NY, USA, 2004.

[11] S. J. Dyke, B. F. Spencer Jr., P. Quast, D. C. Kaspari Jr., and M. K. Sain, "Implementation of an active mass driver using acceleration feedback control," Microcomputers in Civil Engineering, vol. 11, no. 5, pp. 305-323, 1996. 


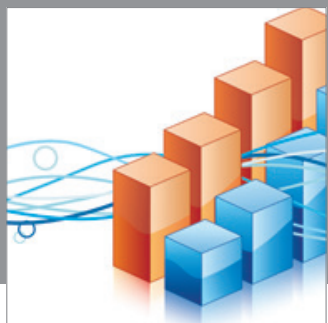

Advances in

Operations Research

mansans

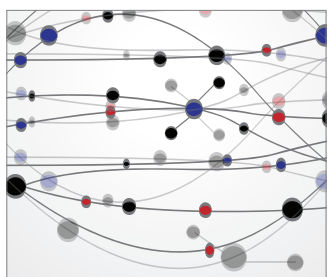

The Scientific World Journal
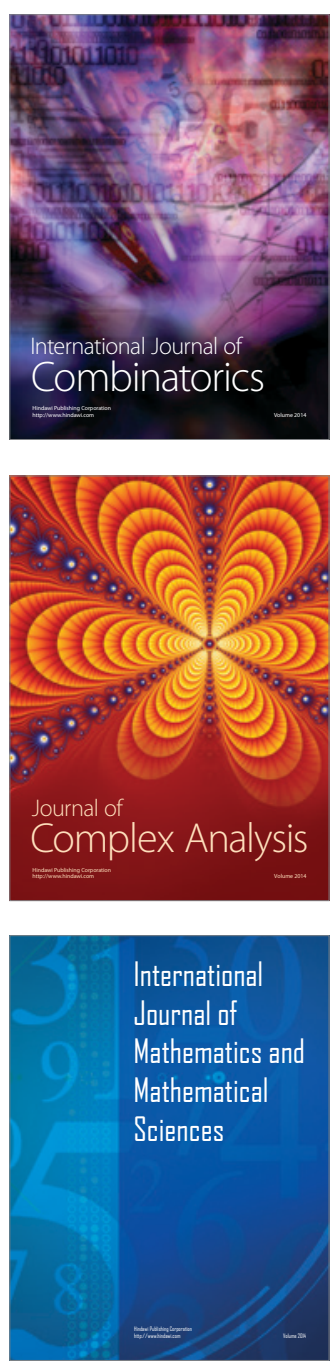
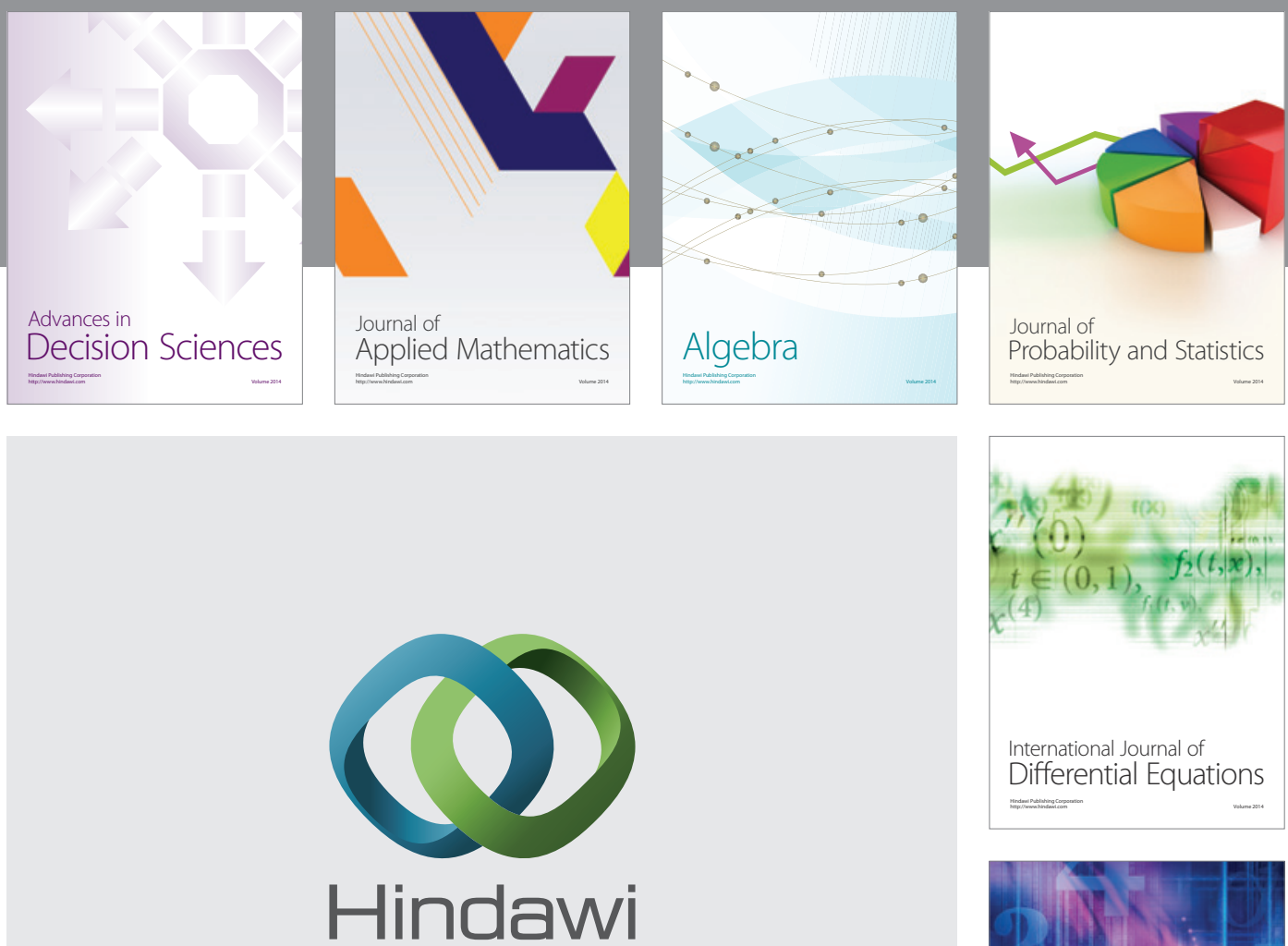

Submit your manuscripts at http://www.hindawi.com
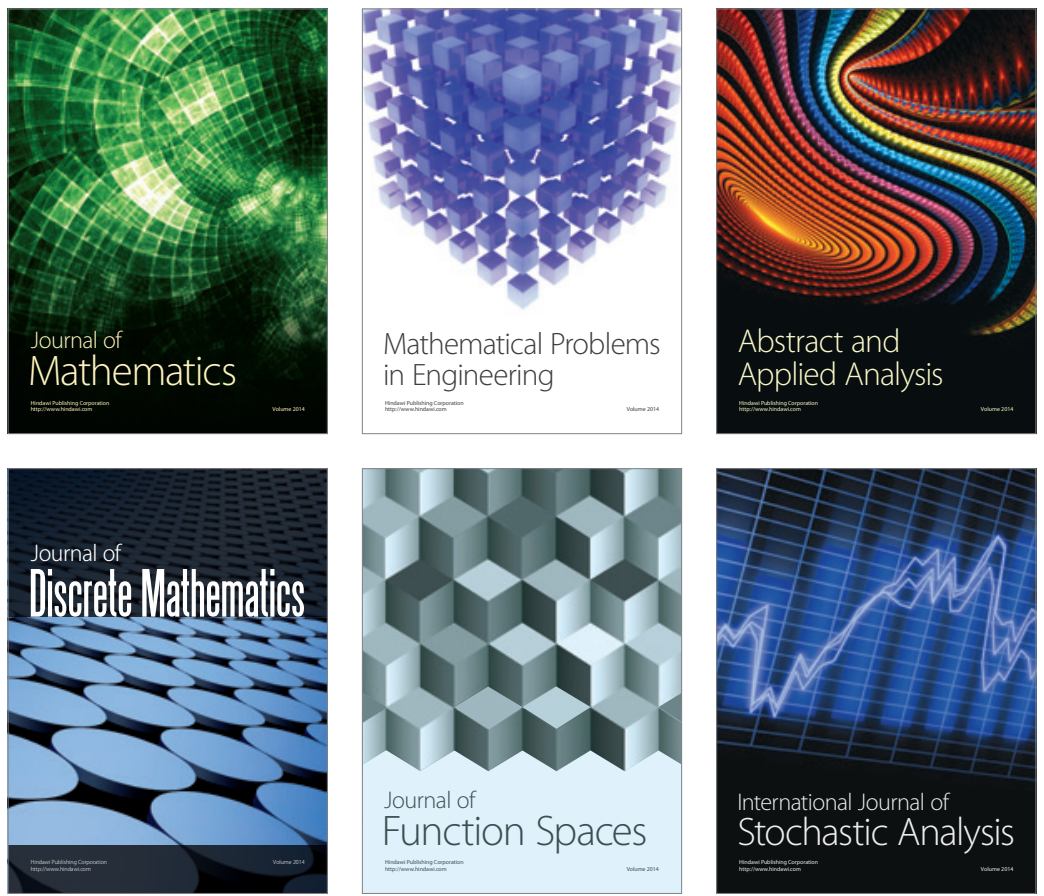

Journal of

Function Spaces

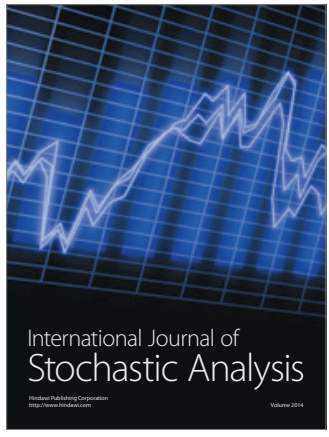

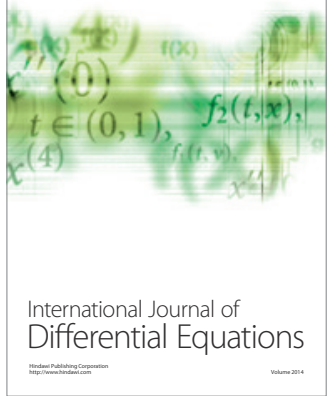
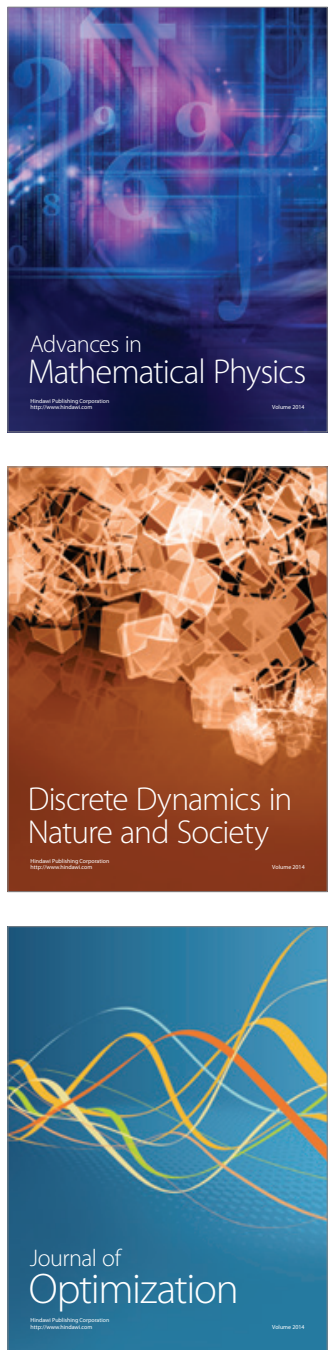